\title{
Talkativeness and verbal aptitude: Perception and reality
}

\author{
R. BARRY RUBACK and JAMES M. DABBS, JR. \\ Georgia State University, Atlanta, Georgia
}

\begin{abstract}
Little attention has been given to the implicit theories linking or the actual relationship between talkativeness and aptitude. In this study, we hypothesized a positive relationship between verbal aptitude and amount of talking. A correlational analysis was conducted using subjects' scores on the verbal section of the Scholastic Aptitude Test and how much they talked while getting acquainted or solving a group problem. Verbal aptitude proved to be unrelated to overall amount of talking but was positively related to pausing between the vocalizations within each speaker's turn.
\end{abstract}

Folk wisdom is not very helpful in describing the relationship between talkativeness and aptitude. According to an Italian proverb, "Half a brain is enough for him who says little." Similarly, in Act 1 of "A Woman of No Importance," Oscar Wilde wrote that "the clever people never listen, and the stupid people never talk" (1894/1969, p. 36). However, even though we may assume that a positive relationship exists between talkativeness and aptitude, we are also aware that quiet individuals can be intelligent, because we know that "still waters run deep."

The notion that aptitude is revealed through one's speech is widespread. Research suggests that intelligent people are expected by both lay individuals and by experts to be verbally fluent and to converse easily (Sternberg, Conway, Ketron, \& Bernstein, 1981). Similarly, there is research linking faster speech rates to perceived intelligence and knowledge (e.g., Apple, Streeter, \& Krauss, 1979; Miller, Maruyama, Beaber, \& Valone, 1976). However, there is little specific research on the relationship between talkativeness and intelligence.

In general, research indicates that amount of talking per se is an important determinant of interpersonal judgments (e.g., Hayes \& Meltzer, 1972). More specifically, Daly, McCroskey, and Richmond (1977) found a positive, linear relationship between amount of vocal activity and perceptions of competence, such that members of small groups who were described as speaking $60 \%$ of the time (about the maximum that would probably occur) were judged more competent than were individuals who spoke lesser amounts.

To determine the implicit theories people have linking talkativeness and intelligence, we asked 63 students (21 males and 42 females) in two introductory psychology classes to complete a brief questionnaire. Half of these subjects $(n=32)$ were asked to think about very talkative individuals and rate them on six scales, including intelligence. The other half of the subjects $(n=31)$ were asked

R. Barry Ruback's mailing address is: Department of Psychology, Georgia State University, Atlanta, GA 30303. to think about very intelligent people and rate them on six scales, including talkativeness. Each scale had five points ranging from -2 (very much below average) to 2 (very much above average), with 0 as average. For people presented as very talkative, the mean rating of intelligence was 0.44 , which was significantly above the midpoint of the scale $[t(31)=3.71, p<.001]$. For this test, the effect size was .66 and the power for a two-tailed alpha level of .05 was .73 . For people presented as very intelligent, the mean rating of talkativeness was 0.32 , which was in the direction of being above average, but not significantly so $[t(30)=1.66, p<.10]$. For this test, the effect size was .29 and the power for a two-tailed alpha level of .05 was .21 . The results suggest that people perceive very talkative individuals to be of above average intelligence, although very intelligent people are not necessarily perceived as being very talkative.

If individuals perceive a connection between talkativeness and intellectual ability, the next question is whether this relationship actually exists. Research on leadership in small groups implies that there is a positive relationship between amount of speech and intelligence. A common finding in the small group literature is that individuals who talk more are more likely to be rated as leaders (Bass, 1981); the average correlation across studies is .65 (Stein $\&$ Heller, 1979). In addition, evidence suggests positive correlations between rated leadership and scores on standard intelligence tests; across 33 studies, Stogdill reported an average correlation of .28 (Bass, 1981). This pattern of correlations suggests a positive link between intelligence and talking.

Although research has investigated the effect of speech on perceptions of the speaker, only a few studies have investigated the actual relationship between intelligence and talking. McCroskey, Daly, and Sorenson (1976) reported no relationship between intelligence and a selfreport measure of communication apprehension. In an analysis of conversations involving inmates being interviewed by a parole officer, Ruback and Hopper (1986) found that inmates with higher IQ scores tended to give 
longer answers than did inmates with lower scores. Matarazzo, Wiens, and Manaugh (1975) examined the relationship between verbal IQ, as measured by the Wechsler Adult Intelligence Scale (WAIS), and three measures of speech and silence behavior under three different speaking conditions. When the subjects (30 job applicants) were in peer-peer dyads, either speaking spontaneously or on instructed topics, no relationship between speech variables and WAIS measures emerged. In contrast, when a clinical psychologist interviewed the applicants individually, verbal IQ was positively related to the mean duration of utterances across different periods within the conversation and across different conversational topics. In addition, a few correlations suggested a positive relationship between verbal IQ and longer pauses before speaking, particularly during the first $15 \mathrm{~min}$ of the 45-min interview.

The purpose of the present study was to determine the relationship between talkativeness and verbal aptitude using 5-person peer groups rather than dyads, as used in Matarazzo et al.'s (1975) study. In light of the research showing a connection between talking and perceived intelligence, we expected that a positive correlation between talkativeness and verbal aptitude would emerge. We chose verbal aptitude because we assumed that it would be the most likely of the components of intelligence to be revealed through talking. In addition, the study investigated the relationship between verbal aptitude and other vocal parameters relating to silences in conversation. We made no specific hypotheses about these latter variables, which are described in more detail below, since the research on these questions was exploratory.

\section{METHOD}

Two samples provided the data for this study. The first sample came from a study involving 100 subjects, 10 male and 10 female groups of 5 undergraduate students each (Dabbs \& Ruback, 1984). Subjects in these groups spent 20 min getting acquainted with each other, talking about anything they wanted. The second sample came from an investigation of the effects of observation on the amount of talking in a group. Subjects (18 males and 27 females) worked in mixed-sex groups of 5 for $10 \mathrm{~min}$ on a problem-solving task, the desert survival situation. They were then interrupted, and 4 of the 9 groups were made aware that they were being observed, so as to increase their arousal. All groups then talked about the problem for an additional $10 \mathrm{~min}$. This procedure was stopped after 9 groups were run, because there were no indications that the manipulation actually made the subjects more aroused. Because the arousal manipulation was not effective, it will not be discussed further. Vocal scores for this sample were obtained for each of the two 10-min conversations.

During the studies, subjects in both samples sat in a circle and talked for a total of $20 \mathrm{~min}$. Every subject wore a lavaliere microphone connected to a microcomputer system in an adjacent room. This system, developed by Dabbs and Swiedler (1983), consists of lavaliere microphones, an amplifier, an Apple II computer, and several computer programs. The data in their final form are a stream of on-off scores for each group member assessed for each .25 -sec moment of the conversation.

The data were transferred from the Apple II to a mainframe computer, where the on-off voice scores were converted into psychologically more meaningful codes, including turns, vocalizations, pauses, and switching pauses (Feldstein \& Welkowitz, in press). A turn, roughly the same as a period of "holding the floor," begins when one person starts talking and ends when another person starts talking. Turns consist of vocalizations (sounds emitted by the turn taker), pauses (silences between vocalizations of the turn taker), and switching pauses (the silences between the last vocalization in one turn and the beginning of the next turn). A switching pause can also be considered as the latency before the next person's turn. In addition to these states, the system registers simultaneous speech, which occurs when a second speaker talks in someone else's turn. A final vocal state, talking, is the total amount of time a person emits sounds during a session and includes the person's vocalizations and simultaneous speech. The theoretical maximum for talking is $100 \%$ for each speaker, which would occur when the speaker did not pause between vocalizations and the speaker spoke while the other individuals were also speaking. These vocal states, reported as mean durations or as percentages of the entire conversational period, have been used to understand conversations in social, problem-solving, and brainstorming groups (Dabbs \& Ruback, 1984; Dabbs, Ruback, \& Evans, in press; Ruback, Dabbs, \& Hopper, 1984).

In addition to providing vocal data, most subjects gave us permission to examine their Scholastic Aptitude Test (SAT) scores. The SAT scores included measures of verbal aptitude (verbal score), based on questions examining vocabulary and reading comprehension (Educational Testing Service, 1979). Students taking the SAT in recent years have also completed a Test of Standard Written English (TSWE), which assesses their knowledge of basic principles of grammar and usage. The verbal score is usually considered to be related to the "crystallized ability" cluster of the WAIS (Snow, 1980, p. 36). ${ }^{1}$ We chose to use the SAT scores because the tests are standardized and the scores were available for most of our subjects. Of course, we are aware of the numerous objections that have been raised against the SAT (e.g., Owen, 1985), and we want to caution against overinterpretation of our results.

In the first sample, SAT scores were requested from 80 subjects. Of these, 4 did not give permission to release their scores and 17 were transfer students who did not have their scores on file with the registrar. In the second sample, SAT scores were requested from 45 subjects. Of these, 4 did not give permission and 9 did not have their scores on file with the registrar. Thus, SAT scores were obtained from 59 subjects in the first sample and 32 in the second, for a total of 91 subjects.

Data were also collected on subjects' communication apprehension. In the first sample, the measure used was the Predisposition to Verbal Behavior (PVB; Lustig, 1980). In the second sample, the measure used was the Personal Report of Communication Apprehension (PRCA; McCroskey, 1982). Finally, in both samples, a composite leadership score was created by combining seven peer-rating scales using Kenny's SOREMO program (Kenny, Lord, \& Garg, 1983), which controls for rater bias in round-robin designs.

\section{RESULTS}

The results for each sample are discussed separately. Because the two samples involved relatively few subjects, they were also merged and additional analyses were conducted.

\section{Sample One}

For the 59 subjects in the first sample, SAT verbal scores ranged from 230 to 600 (mean $=433.2$; median $=440.0$ ), and TSWE scores ranged from 21 to 60 (mean $=44.4$; median $=47.0$ ). These scores are slightly above the national average. In terms of the vocal measures, the mean percentage of the session for each of the vocal states for each subject was as follows: turns, $17.9 \%$; vocalizations, $12.8 \%$; pauses, $2.7 \%$; switching pauses, $2.5 \%$; simultaneous speech, $5.0 \%$; talking, $17.8 \%$.

All correlational analyses used pooled within-group correlations to control for mean differences between groups, that is, for the fact that each group is unique. Con- 
trary to expectations, verbal aptitude was not related to vocalization ( $r=.14$, n.s.) or to total talking ( $r=0.11$, n.s.). The power of these tests for a "medium'" effect size of $r=.30$, a sample size of 59, and a two-tailed alpha level of .05 is .65 (Cohen, 1977). None of the other correlations of verbal aptitude with the vocal measures was significant, although the correlation between the latency before a turn and the SAT verbal score was marginally significant $(r=.22, p<.10)$. Individuals with higher SAT verbal scores tended to spend more time in the silences before they started talking. Visual inspection of scatter plots of verbal aptitude against each of the vocal measures gave no suggestion of a curvilinear relationship.

Apparently the amount of talking per se is not a good predictor of verbal aptitude. However, the relationship might be more complex. For example, folk wisdom might suggest a bimodal distribution, with high aptitude related to either high or low levels of talking. To test this notion, we partialled amount of talk out of the relationships between the SAT verbal score and the remaining vocal measures. None of the partial correlations was significant.

In addition to these correlations, students' SAT scores were correlated with their peers' ratings of their leadership in the group and with a measure of communication apprehension (the PVB). Students rated high in leadership tended to have higher scores on the TSWE $(r=.47$, $p<.05)$. Students with less communication apprehension tended to score higher on the TSWE $(r=-.47$, $p<.05)$ and were more likely to be rated as leaders $(r=-.41, p<.001)$. The correlation between vocalizing and the PVB was $r=-.45, p<.001$, and the correlation between vocalizing and rated leadership was $r=.69, p<.001$. To test whether communication apprehension mediates the relationship between verbal aptitude and the vocal measures, we partialled PVB out of the correlations among the measures. None of these partial correlations was significant.

\section{Sample Two}

For the 32 subjects in the second sample, SAT verbal scores ranged from 250 to 590 (mean $=434.7$; median $=430.0$ ), and TSWE scores ranged from 23 to 59 (mean $=41.3$; median $=43.0$ ). For each of the vocal states for each subject, the mean percentage for the two 10-min sessions was as follows: turns, 19.6\%; vocalizations, $11.8 \%$; pauses, $3.5 \%$; switching pauses, $4.2 \%$; simultaneous speech, $2.6 \%$; talking, $14.5 \%$.

Correlational analyses revealed that the SAT verbal score was not significantly related to the amount of vocalizing for the first 10 -min period, the second 10-min period, or to the average of the two periods (all $r s<.13$, n.s.). There were also no significant correlations between the SAT verbal score and the measures of talking, turns, switching pauses, or simultaneous speech for the first or second period or for the average of the two periods. A significant relationship did emerge between the SAT verbal score and pausing during the first 10 -min period $(r=.37, p<.05)$, but no significant effects emerged for the second $10-\mathrm{min}$ period $(r=.20$, n.s.) or for the average of the two periods $(r=.30, p=.10)$. The power of all of these correlations for an effect size of $r=.30$, a sample size of 32 , and a two-tailed alpha of .05 is .39 , which is relatively low. As with the prior sample, visual inspection of scatter plots of verbal aptitude against each of the vocal measures yielded no indication of a curvilinear relationship.

When talking was held constant, as in the first sample, pausing and the SAT verbal score were found to be significantly related for the average of the two time periods $(r=.40, p<.05)$ and for the first time period $(r=.45$, $p<.01)$, but only marginally related for the second time period ( $r=.30, p=.10$ ). For the first time period, a significant correlation also appeared between time in turns and the SAT verbal score $(r=.36, p<.05)$. The effect was not significant for the second time period ( $r=.25$, n.s.) and was only marginally significant for the average of the two periods $(r=.34, p=.06)$.

Subjects with less communication apprehension, as measured by the PRCA, tended to spend more time vocalizing $(r=-.40, p<.05)$, more time talking $(r=-.37, p<.05)$, and marginally more time in turns $(r=-.32, p<.07)$. Partialling out communication apprehension from the correlations between the SAT measures and the vocal measures did not reveal any significant relationships. A significant relationship appeared between the SAT verbal score and rated leadership $(r=.39, p<.05)$; leaders tended to have higher verbal aptitude.

\section{Merged Samples}

Because the two samples separately had relatively few subjects, we decided to merge them to increase to .83 the power to detect a correlation of $r=.30$, at a two-tailed alpha level of .05. Across the two samples, only the amount of time subjects spent in pauses was significantly related to the SAT verbal score $(r=.22, p<.05)$. Even when talking was partialled out of the relationships between the SAT verbal score and the remaining vocal measures, only the partial correlation between pausing and the SAT verbal score was significant $(r=.22, p<.05)$, although there was a marginally significant relationship between time in turns and the SAT verbal score $(r=.18$, $p=.08)$.

\section{DISCUSSION}

This study contains two rather surprising findings. First, contrary to folk wisdom, verbal aptitude appears to be unrelated to talkativeness. This finding is unexpected because this study and much prior research (see Bass, 1981) have found both verbal ability and talkativeness to be related to leadership. The results of this study are consistent with Matarazzo et al.'s (1975) failure to find a relationship between verbal IQ and vocalization measures in peer-peer dyads. Perhaps verbal IQ is manifested in speech only during situations in which creating a good impression is very important, such as during job interviews (Matarazzo et al., 1975) or parole interviews (Ruback \& Hopper, 1986).

The second surprising finding is that verbal aptitude appears to be related to silence, specifically the time spent in the pauses between vocali- 
zations. One possible explanation is that the speaker is thinking during these periods of silence and that individuals with greater verbal aptitude are more likely to ensure that their speech is correct by pausing to think about it. This possibility may explain why Matarazzo et al. (1975) found a tendency for job applicants with higher WAIS verbal scores to have longer latencies before speaking. Since in the second sample, we found the relationship between pausing and verbal aptitude to be stronger during the first $10 \mathrm{~min}$ than during the last $10 \mathrm{~min}$, aptitude may be more evident in speech during the initial phases of a conversation.

Our finding that silence is related to verbal aptitude is consistent with other evidence indicating the importance of silences. For example, in a study of brainstorming groups, Ruback et al. (1984) found that ideas tended to be preceded by periods of silence (switching pauses). In addition, evidence from that study and a study of problem-solving groups (Dabbs et al., in press) indicates that, compared with nonleaders, leaders tend to have a greater percentage of time in switching pauses ending their turns and in latencies before their turns.

Two caveats are necessary about the results of this study. First, the use of SAT scores to indicate verbal aptitude has limitations. A student's knowledge of vocabulary and grammar, which is measured by the SAT, is only one component of verbal aptitude. Future studies might investigate other aspects of verbal aptitude, such as fluency in foreign languages. A second caution concerns the generalizability of these findings. Although our procedure accurately measures the vocal behavior of laboratory groups, vocal behavior may be quite different in freeranging conversations outside the laboratory. Future research needs to investigate whether the present findings hold true for natural situations, for other kinds of group tasks, and for larger and smaller groups.

\section{REFERENCES}

Apple, W., Streeter, L. A., \& Krauss, R. M. (1979). Effects of pitch and speech rate on personal attributions. Journal of Personality \& Social Psychology, 37, 715-727.

BAss, B. M. (1981). Stogdill's handbook of leadership. New York: Free Press.

COHEN, J. (1977). Statistical power analysis for the behavioral sciences. New York: Academic Press.

DabBs, J. M., JR., \& Ruback, R. B. (1984). Vocal patterns in male and female groups. Personality \& Social Psychology Bulletin, 10, 518-525.

Dabbs, J. M., JR., Ruback, R. B., \& Evans, M. S. (in press). Grouptalk: Patterns of sound and silence in group conversation. In. A. W. Siegman \& S. Feldstein (Eds.), Nonverbal behavior and communication (2nd ed.). Hillsdale, NJ: Erlbaum.

Dabbs, J. M., JR., \& Swiedler, T. C. (1983). Group AVTA: A microcomputer system for group voice chronography. Behavior Research Methods \& Instrumentation, 15, 79-84.

Daly, J. A., McCroskey, J. C., \& Richmond, V. P. (1977). Relationships between vocal activity and perception of communicators in small group interaction. Western Journal of Speech Communication, 41, 175-187.

Educational Testing Service. (1979). Taking the SAT: A guide to the Scholastic Aptitude Test and the Test of Standard Written English. Princeton, NJ: College Entrance Examination Board.
Feldstein, S., \& Welkowitz, J. (in press). A chronography of conversation: In defense of an objective approach. In A. W. Siegman \& S. Feldstein (Eds.), Nonverbal behavior and communication (2nd ed.). Hillsdale, NJ: Erlbaum.

Hayes, D., \& Meltzer, L. (1972). Interpersonal judgments based upon talkativeness: Fact or artifact. Sociometry, 35, 538-561.

KENNY, D. A., LoRD, R. G., \& GARG, S. (1983). A social relations analysis of peer ratings. Unpublished manuscript, University of Connecticut.

Lustig, M. W. (1980). Computer analysis of talk-silence patterns in triads. Communication Quarterly, 28(4), 3-12.

Matarazzo, J. D., Wiens, A. N., \& Manaugh, T. S. (1975). IQ correlates of speech and silence behavior under three dyadic speaking conditions. Journal of Consulting \& Clinical Psychology, 43, 198-204.

McCroskey, J. C. (1982). Oral communication apprehension: A reconceptualization. In M. Burgoon (Ed.), Communication yearbook 6. Beverly Hills, CA: Sage.

McCroskey, J. C., Daly, J. A., \& Sorenson, G. A. (1976). Personality correlates of communication apprehension. Human Communication Research, 2, 376-380.

Miller, N., Maruyama, G., Beaber, R. J., \& Valone, K. (1976). Speed of speech and persuasion. Journal of Personality \& Social Psychology, 34, 615-634.

OWEN, D. (1985). None of the above: Behind the myth of scholastic aptitude. Boston: Houghton Mifflin.

Ruback, R. B., Dabbs, J. M., JR., \& HopPeR, C. H. (1984). The process of brainstorming: An analysis with individual and group vocal parameters. Journal of Personality \& Social Psychology, 47, 558-567.

Ruback, R. B., \& Hopper, C. H. (1986). Decision making by parole interviewers: The effect of case and interview factors. Law \& Human Behavior, 10, 203-214.

SNow, R. E. (1980). Aptitude processes. In R. E. Snow, P. Federico, \& W. E. Montague (Eds.), Aptitude, learning, and instruction (Vol. 1). Hillsdale, NJ: Erlbaum.

Stein, R. T., \& Heller, T. (1979). An empirical analysis of the correlations between leadership status and participation rates reported in the literature. Journal of Personality \& Social Psychology, 37, 1993-2002.

Sternberg, R. J., Conway, B. E., Ketron, J. L., \& Bernstein, M. (1981). People's conceptions of intelligence. Journal of Personality \& Social Psychology, 41, 37-55.

WILDE, O. (1894/1969). A woman of no importance. London: Methuen.

\section{NOTE}

1. In a telephone call to the Educational Testing Service to find the correlation between WAIS and the SAT Verbal, we learned that this information is "not available."

(Manuscript received for publication June 17, 1986.) 